\title{
A ANÁLISE ECONÔMICA DO DIREITO E OS CUSTOS OCULTOS DE TRANSAÇÃO EM MATÉRIA TRIBUTÁRIA
}

\author{
ECONOMIC ANALYSIS OF LAW AND THE TRANSACTION COSTS \\ ON TAX MATTERS
}

\section{Marcia Carla Pereira Ribeiro}

\begin{abstract}
Doutora em Direito pela Universidade Federal do Paraná (UFPR). Professora de Direito Empresarial da PUCPR e da UFPR. Estágio de Pós-doutorado na EDESP/FGV e pela Faculdade de Direito da Universidade de Lisboa. Pesquisadora Conv.Université de Montréal - CA. Advogada.

E-mail: mcarlaribeiro@uol.com.br
\end{abstract}

Barbara das Neves

Mestre em Direito do Estado (ênfase em Direito Tributário) pela Universidade Federal do Paraná. Especialista em Direito Tributário pelo Instituto Brasileiro de Estudos Tributários (IBET). Graduada em Direito pelo Centro Universitário Curitiba (UNICURITIBA) e em Ciências Contábeis pela Universidade Federal do Paraná. Advogada e Professora E-mail: barbaradasneves@gmail.com.

Recebido em: 18/12/2018

Aprovado em: 27/05/2020

RESUMO: O presente artigo visa analisar a aplicação da Análise Econômica do Direito (AED), especificamente ao Direito Tributário, responsável pela regulação de determinadas condutas dos agentes econômicos. Assumindo a premissa de que o tributo é necessário ao próprio funcionamento da máquina pública, procura-se demonstrar de que maneira a AED pode auxiliar na busca pela eficiência da arrecadação e validação das regras jurídicas. Para tanto, o artigo analisa de que maneira a própria tributação e, especialmente, os deveres instrumentais podem ser identificados como custos de transação, muitas vezes ocultos. Por fim, sugere-se a análise dos limites à imposição de prestações de fazer contrapostas aos direitos de sigilo dos contribuintes e que podem resultar em verdadeiros prejuízos às atividades econômicas envolvidas. A metodologia utilizada neste artigo foi a pesquisa bibliográfica, com a técnica de pesquisa direta e método de abordagem dedutivo.

Palavras-chave: Tributação. Análise Econômica do Direito. Custos de Transação. Direitos de Sigilo.

ABSTRACT: The objective of the following article is to analyze the application of the Economic Analysis of Law (EAL) specifically to the field of Tax Law responsible for regulating the conduct of economic agents. Assuming the premise that the tribute is necessary to the very operation of the public machine, this article aims to demonstrate how the EAL can help in the search of efficiency in taxation and validation of legal rules. To achieve this goal, this article seeks to analyze how taxation itself, and especially instrumental duties, can be identified as transaction costs, often 
hidden. Finally, the article endeavors in the analysis of the limits of imposing duties in opposition to the right of secrecy of the taxpayers and the risk of real damages to the economic activities involved. This article uses the bibliographical research method, based on direct and deductive techniques.

Keywords: Taxation. Economic Analysis of Law. Transaction Costs. Data Secrecy.

SUMÁRIO: Introdução; 1. A Análise Econômica do Direito; 2. A Análise Econômica do Direito e os Custos de Transação; 3. Os Deveres Instrumentais como Custos de Transação; 4. Os Deveres Instrumentais e o Sigilo de Dados; Considerações Finais; Referências.

\section{INTRODUÇÃO}

A Constituição Federal de 1988, em razão da conformação do Estado Democrático de Direito, enumera os objetivos constitucionais voltados a assegurar os direitos essenciais dos cidadãos brasileiros, tendo por meta fundamental a consolidação de uma sociedade livre, justa e solidária.

Historicamente, os tributos foram criados para proporcionar a principal fonte de recursos necessária para o financiamento do modelo escolhido de Estado, o que acentua sua função socioeconômica para a prática de políticas públicas e demais atividades de regulação e polícia.

Porém, há que se reconhecer o fato que o Brasil passa por uma profunda crise de legitimidade das atividades vinculadas ao Poder Público, dentre elas as que envolvem a atividade arrecadatória e fiscalizatória que, a despeito de serem extremamente eficientes do ponto de vista arrecadatório, não revertem necessariamente em benefícios para a sociedade e o desenvolvimento econômico de suas organizações.

Ao mesmo tempo em que a exigência de tributos e toda burocracia dela decorrente é justa e compatível com o ordenamento jurídico na perspectiva fazendária, para os contribuintes a tributação muitas vezes faz aflorar um sentimento de injustiça e de caráter confiscatório, em especial em virtude de uma carga excessivamente elevada e de uma sintomática precariedade na gestão das finanças públicas.

As crises econômicas passaram a ser compreendidas como sinônimas da necessidade do aumento de tributos, sem que tais incrementos fossem justificados pela real finalidade tributária para fins de promoção do desenvolvimento nacional e também eficiência do próprio sistema.

Evidentemente, o Estado necessita de recursos para manutenção de sua estrutura e concretização dos objetivos constitucionais e, para tanto, precisa de mecanismos de controle e regulação. No entanto, a tributação não deve ser utilizada como recurso para o custeio de ações administrativas pouco eficientes ou apenas com fins meramente arrecadatórios, sem uma vinculação aos propósitos constitucionais.

Pelo contrário, a distribuição do encargo tributário deve ser realizada de maneira eficiente, sem distinção autoritária baseada em políticas de interesse ou conveniência desassociadas de um objetivo prévio que seja o próprio desenvolvimento da sociedade e da economia do país.

A atual desconfiança por parte da população, os grandes custos de transação e a imprevisibilidade da carga tributária aumentam a demanda por reformas no sistema tributário e afastam cada vez mais inovações e investimentos na economia do país. A partir deste contexto, não são poucos os estudos sobre as possíveis formas de otimização da carga tributária e da complexidade do sistema.

A despeito de possíveis críticas sobre a interdisciplinaridade do direito a outros sistemas sociais, no atual contexto econômico é praticamente impossível desassociar o âmbito jurídico da realidade socioeconômica. 
Não se pretende, por meio deste trabalho, analisar a aplicabilidade desta perspectiva ao Direito como um todo, mas, sim, refletir sobre as consequências, especialmente econômicas, que não devem ser ignoradas ao se analisar o sistema tributário que, por sua natureza, representa um ônus, com custos diretos e indiretos muitas vezes desconsiderados, em proveito de uma maior facilidade na arrecadação ou fiscalização do agente arrecadador.

Assim, inicialmente, adotando algumas das importantes contribuições da Economia à análise de custos e desenvolvimento econômico, o presente artigo busca analisar o que seriam os chamados custos de transação e de que maneira tais instrumentos afetam a sociedade e, especificamente quanto ao objeto de estudo, sob a perspectiva tributária.

Na sequência, analisa-se de que maneira os deveres instrumentais (obrigações acessórias) podem ser compreendidos como verdadeiros custos ocultos de transação em matéria tributária, inviabilizando determinadas atividades ou mesmo desincentivando o cumprimento de normas e recolhimento de tributos.

Por fim, discute-se sobre quais são os limites impostos à Administração Pública para que novas imposições surjam e limitem a atividade econômica, seja pela atribuição de custos onerosos ao cumprimento das prestações ou mesmo para a divulgação de informações sigilosas que impõe riscos ao desenvolvimento da própria atividade em análise.

\section{A ANÁLISE ECONÔMICA DO DIREITO}

Pode-se compreender a Análise Econômica do Direito - AED como a utilização de recursos e conhecimentos das Ciências Econômicas para a compreensão dos efeitos da criação e aplicação de regras jurídicas.

Como observa Carvalho (2006, p. 81-88), a Análise Econômica do Direito decorre de um conhecimento interdisciplinar que busca "desenvolver ferramentas epistemológicas não originalmente disponíveis na Ciência Jurídica ou na Ciência da Economia". Ou seja, surge como uma reação à ideia de que o direito deveria ser compreendido completamente de maneira autônoma e apenas com base em precedentes do passado, propondo-se uma extensão desta perspectiva à realidade social, especificamente no que se refere aos impactos das normas propostas ou vigentes.

O movimento que se denominou Análise Econômica do Direito é extremamente complexo, cujas ideias divergem entre si em determinados aspectos como a Escola das Escolhas Públicas, Escola de Chicago e a Escola da Nova Economia Institucional.

Especificamente em matéria tributária, a doutrina tradicional no Brasil defende a análise apenas sob a perspectiva sintática e semântica das normas instituidoras, fiscalizadoras e arrecadadoras de tributos. Ou seja, procura descrever o Direito a partir dos enunciados prescritivos já produzidos.

No entanto, é evidente que o Direito se volta à regulação das relações sociais e, como tal, não deve ficar completamente alheio aos resultados a elas impostos pela criação e aplicação prévia das regras jurídicas (pragmatismo). Afinal de contas, afirmar o contrário seria negar seu próprio objeto - a efetividade da regulação de condutas.

A partir dessa interligação entre campos diferentes de conhecimento, busca-se analisar os reais impactos da elaboração de regras jurídicas e suas aplicações dentro das relações sociais (objeto do próprio Direito). Os efeitos poderão ser bons ou ruins, inclusive, gerando consequências distintas daquelas inicialmente previstas, motivo pelo qual a análise econômica se preocupa em compreender a razão de tais consequências no ambiente econômico.

Quanto à interdisciplinaridade do direito e a economia, Ribeiro e Galeski Junior (2015, p. 83) explicam que a junção dos conhecimentos pode se dar em qualquer ramo do Direito, desde uma perspectiva mais evidente como o direito de concorrência e contratos, até em determinadas áreas de mais difícil aplicação, como no Direito Penal, Família, e também no Direito Tributário. 
Sob esta perspectiva, utilizar a AED torna-se especialmente interessante ao Direito Tributário, principalmente diante dos impactos potenciais de novas obrigações sobre os contribuintes.

Afinal de contas, a AED pressupõe uma escolha racional dos agentes (indivíduos nas condutas humanas), com base em determinadas preferências. Por esta razão, com base em técnicas da Economia, como custos de transação, de oportunidade, dentre outras, seria possível determinar ou ao menos compreender os resultados da aplicação e criação das regras jurídicas que regulam o convívio em sociedade.

Aliás, o Direito não pode (e nem deve) permanecer alheio às constantes alterações nas relações sociais, sob pena de se tornar inócuo e defasado. Por esta razão, seria impossível neutralizar a análise do Direito em relação aos possíveis efeitos econômicos dele decorrentes.

O tributo e as demais prestações não pecuniárias dele resultantes devem estar associados (se não condicionados) à realização dos objetivos constitucionais e à manutenção do aparato estatal, desde que não caracterize um instrumento que venha a prejudicar o desenvolvimento da própria sociedade, diante do risco de se ter por questionada a legitimidade da imposição estatal.

Silveira (2009, p. 17-18), ao analisar a aplicabilidade do estudo econômico à tributação, explica que toda economia depende de um financiamento com objetivo de arcar com os custos vinculados à organização institucional. Por esta razão, existem duas principais preocupações na teoria econômica: equidade e eficiência. Isso porque "o Estado deve implementar suas políticas com o mínimo de efeitos para a sociedade (minimun loss to society)" e, ainda, "deve agir para obter a mais equitativa distribuição de bens na sociedade, especialmente, perante o fato de vivermos em uma sociedade em que o mercado é imperfeito [...]".

Ora, é preciso avaliar os reais impactos da aplicação das regras jurídicas vigentes de modo a se concluir pela manutenção e pertinência dos objetivos anteriormente propostos. É preciso que se questione, por exemplo, se a exigibilidade de certa prestação perante o contribuinte se justifica, caso os custos de fiscalização sejam por demais onerosos, superando ou não a opção impositiva do Estado.

Neste sentido, um Poder Judiciário consistente, um ambiente negocial que possibilite a execução de contratos de maneira eficiente e direitos de propriedade bem definidos possibilitam o incremento dos financiamentos às atividades econômicas, fruto da segurança quanto às possíveis consequências no caso de descumprimento das condições estabelecidas pelas partes. Em contrapartida, um direito considerado "fraco" pode afastar estes mesmos investimentos, em face do receio das organizações envolvidas na operação (COOTER, 2017, p. 51).

A mesma perspectiva lógica pode ser aplicada em busca da eficiência do sistema tributário e da gestão pública.

No Brasil, a dificuldade da relação entre os gastos públicos e o aumento da carga tributária já é antigo. Isso porque é habitual a utilização do aumento da carga tributária e da complexidade do sistema como soluções às crises financeiras e institucionais, independentemente da devida análise da repercussão econômica das medidas em relação aos contribuintes e à sociedade.

Tais práticas contam, ainda, com um grande aliado para sua concretização: o desconhecimento público acerca da real carga tributária em face especialmente da complexidade do sistema.

Os tributos indiretos, cuja repercussão econômica é repassada aos destinatários da cadeia econômica, são importantes exemplos da distorção do sistema tributário nacional (VIVERDOS DE CASTRO, 1989, p. 132). Os chamados bens de primeira necessidade são excessivamente onerados (roupas, alimentos, energia) sem a devida análise sobre a carga tributária final efetiva imputada aos mesmos contribuintes, fruto da cobrança dos tributos brasileiros (nos níveis municipal, estadual e federal), além da taxação direta do trabalho, da propriedade e da renda.

Veja-se, por exemplo, uma operação cujo valor de venda de energia elétrica teria sido originalmente estabelecido na quantia de $\mathrm{R} \$ 100,00$ (cem reais). Supondo-se a realização de uma 
operação de revenda da energia sujeita à alíquota nominal de $25 \%$ pela incidência do ICMS (percentual padrão ao Imposto sobre a Operação de Circulação de Mercadorias de energia elétrica), chega-se a uma base de cálculo de $\mathrm{R} \$ 133,33$ do imposto, na medida em que a sistemática de cálculo do tributo pressupõe a incorporação do próprio imposto a sua base de cálculo ${ }^{1}$.

Ao aplicar a referida alíquota de $25 \%$ sobre a base de cálculo indicada, a conclusão é a de que o valor final devido pelo contribuinte será de $\mathrm{R} \$ 33,33$, que representa uma carga efetiva de $33 \%$ quando comparado ao valor original de $\mathrm{R} \$ 100,00$ (e não a alíquota de $25 \%$ indicada originalmente na legislação). Ou seja, o custo é majorado em 8 pontos percentuais à alíquota previamente informada pela legislação.

Outro exemplo decorre da distorção do sistema de concessão de vantagens tributárias sem que existam políticas extrafiscais suficientemente justificadas para o tratamento diferenciado. Sob a justificativa de que determinados setores deveriam ser agraciados com possíveis incentivos ao desenvolvimento de suas operações, ou mesmo em razão dos possíveis resultados benéficos em prol da sociedade (em termos regionais ou nacionais), concedem-se benefícios ou incentivos fiscais que afastam, em parte ou na totalidade, o encargo tributário ${ }^{2}$ (Supremo Tribunal Federal, 2015).

Conforme explicam Cooter \& Schafer (2017, p. 65), as isenções dos impostos reduzem a visibilidade das transferências para determinados grupos favorecidos, o que seria prejudicial ao mercado em geral e aos cofres públicos. Ou seja, caso se trate de um benefício sem propósito, a desoneração acaba por resultar em uma concorrência desleal, para além da condição de benefício conferido a determinado setor da economia.

Obviamente, não se está questionando aqui os incentivos fiscais que revertem em benefícios comprovados para a sociedade e que utilizam o tributo como mecanismo de inclusão social (extrafiscalidade) e de desenvolvimento econômico.

O fundamento da tributação está justamente em sua íntima ligação com a própria finalidade do Estado, pensando-se em termos de promoção do desenvolvimento da sociedade brasileira.

No entanto, os benefícios fiscais, ou seja, os que correspondam exonerações sem condições pré-estabelecidas (GRUPENMACHER, 2012, p.17), caso concedidos de maneira não planejada, podem representar exatamente o oposto dos objetivos inicialmente propostos pela administração pública, já que a redução arrecadatória não seria acompanhada de benefícios compensatórios efetivos a justificá-la.

Tome-se, como exemplo, a redução da alíquota do Imposto sobre a Importação (II) que produza um desequilíbrio no mercado que conduza a eliminação da produção nacional de determinado produto a ponto de resultar uma situação de monopólio pelo encerramento das atividades de potenciais concorrentes internos.

A situação pode se agravar de forma proporcional ao porte das empresas beneficiadas ao se considerar que empresas que ocupam posição dominante em determinados mercados detêm poder de barganha expressivo e a possibilidade de mobilização e transferência de recursos voltados a influenciar setores políticos e da administração pública.

Em resumo, é expressiva a potencialidade de inconsistências nas políticas tributárias, cujos resultados nas relações sociais podem estar dissociados dos objetivos inicialmente propostos pela Administração Pública e pelas regras jurídicas existentes no ordenamento.

\footnotetext{
${ }^{1}$ Trata-se de cálculo bastante simples, sem levar em consideração os demais tributos e margens incorporados ao preço de venda e repassados aos destinatários. Ou seja, apenas considerando o cômputo do tributo em sua própria base de cálculo, no cálculo "por dentro".

${ }^{2}$ Exemplos de benefícios fiscais concedidos por meio do sistema de créditos presumidos, reduções de base de cálculo e isenção pelos diversos entes da federação em dissonância com o ordenamento jurídico ou da contrapartida econômica em prol do desenvolvimento regional. Cite-se como exemplo a discussão vinculada na ADI 4481/2015, em que uma série de benefícios fiscais relativos ao ICMS foram concedidos pelo Estado do Paraná com base na Lei nº 14.985/2006 e que foram considerados inconstitucionais pelo E. Supremo Tribunal Federal diante do ordenamento jurídico.
}

Revista de Direito Brasileira | Florianólopis, SC | v. 25 | n. 10 | p. 266-279 | Jan./Abr. 2020 
Obviamente, assim como pode ocorrer na iniciativa privada, a ineficiência e ausência de planejamento por parte do Estado pode resultar na insuficiência de recursos para a execução das políticas públicas. Ainda, como ressalta Buchanan (2004, p. 284), a classe política do governo é composta por profissionais, sujeitos individuais que não necessariamente agirão em nome do interesse e supremacia do Poder Público.

Trata-se de um ciclo vicioso: quanto maior a carga tributária e a complexidade do sistema, maiores serão os possíveis sonegadores e menor a injeção de investimentos na atividade produtiva geradora de tributos, resultando na insistente necessidade de elevação da carga tributária e dos custos de fiscalização.

Neste sentido, a AED pode ser utilizada como eficiente instrumento para a compreensão de situações como as já apresentadas, auxiliando na busca por um sistema mais eficiente e cujas propostas sejam coerentes com os resultados econômicos e sociais almejados.

\section{A ANÁLISE ECONÔMICA DO DIREITO E OS CUSTOS DE TRANSAÇÃO}

Conforme visto, a AED constitui importante ferramenta também em matéria tributária, na medida em que trabalha com instrumentos que auxiliam na análise da eficiência das imposições que recaem sobre os contribuintes, permitindo-se compreender se tais resultados são compatíveis com os objetivos originalmente propostos pela Administração Pública.

No entanto, existem custos que não são facilmente perceptíveis em matéria tributária, por não ser perfeitamente clara a sua relação com as imposições demandadas pelo fisco.

Neste sentido, torna-se relevante o pensamento de Ronald Coase, vencedor do prêmio Nobel da Economia que analisou o problema do custo das externalidades em sua obra "O Problema do Custo Social". Para o autor, as externalidades podem ser vistas como os ganhos ou prejuízos originalmente não avaliados ou computados no preço de determinada transação, mas que se mostram existentes e que oneram a operação.

Por exemplo, caso certo produtor tenha que considerar não apenas o custo da produção de determinado produto, mas outros desembolsos como viagens para convencer determinados clientes, estes seriam custos de transação necessários à concretização da compra.

São, portanto, efeitos não previstos originalmente, já que existem certos limites de racionalidade nos agentes envolvidos na transação, que podem ser considerados uma derivação da assimetria de informações (COASE, 2010, p. 59-112).

Por exemplo, o autor cita o caso de uma fábrica que produz certa quantidade de fumaça que afeta a vizinhança em que está instalada. Neste caso, a chamada externalidade negativa não está sendo dividida pelos principais envolvidos na situação (produtor e comprador), resultando numa distorção do mercado.

Coase (1960, p. 28) explica que a solução geralmente proposta para este tipo de situação seria ponderar os objetivos privado e público que cercam o tema, de modo a que a solução comum seria a responsabilização do dono da fábrica pelo prejuízo causado com a fumaça. No entanto, para o autor, este tipo de solução nem sempre seria desejável e a melhor a ser aplicada à situação concreta.

Isto porque fazer com que o dono da fábrica pague uma quantia monetária para cada jato de fumaça não significa, necessariamente, proporcionar condições ótimas ao problema apresentado. Por exemplo, com o aumento de moradores da região, o número de pessoas prejudicadas também aumentaria, resultando num montante ainda maior de indenização e prejudicando o desenvolvimento da atividade da fábrica. Sob a perspectiva contrária, caso não existisse nenhuma implicação à fábrica, o número de moradores seria reduzido de maneira drástica (COASE, 1960, p. 33).

Desse modo, o resultado preferível, na opinião do autor, seria a tolerância de parte da fumaça produzida, correspondente ao valor máximo da produção global. Isso porque existiriam 
soluções como a instalação de filtros de chaminés ou o pagamento para o deslocamento dos moradores que seriam mais eficientes para o caso em análise (COASE, 1960, p. 13).

Em outras palavras, a solução proposta parte da possibilidade de negociação dos envolvidos, com um custo menor quando comparado à simples responsabilização ou taxação da atividade da indústria. O resultado será a eficiência da operação acompanhada do incremento do nível de satisfação entre as partes, desde que negociem de maneira livre e que a proposta seja respaldada pelo Direito.

O pensamento de Coase privilegia a negociação em detrimento da prévia definição normativa da solução para o conflito, em proveito da solução mais compatível com o ideal de redução dos custos de transação. Estes são tomados não apenas como custo da produção ou da prestação de serviço, mas da operação (transação) como um todo. Na hipótese de um ambiente de negociação de custo zero, a livre negociação entre as partes, com compensações mútuas, conduziria à solução e alocação das externalidades num cenário ótimo.

A despeito de ser praticamente impossível identificar um cenário de custo zero, o pensamento do autor foi essencial ao aprimoramento da noção de custos de transação e à reflexão sobre a eficiência da norma em comparação com a livre negociação entre as partes, não apenas em relação aos resultados apropriados pelas partes, como também em termos de custos sociais relacionados às externalidades.

Para além da análise dos custos de transação, Silveira (2009, p. 19) explica que o pioneirismo do Coase foi também "levar em conta os motivos que fazem o mercado criar firmas, estabelecer diferentes formas societárias, criar tipos contratuais diversos, montar uma estrutura determinada no sistema financeiro e mesmo regulamentar instituições jurídicas diferentes".

Ou seja, a análise dos custos de transação está na base da existência de diferentes tipos de planejamentos e formas societárias com o objetivo de diminuição dos desembolsos, inclusive custos diretos e indiretos envolvidos na produção ou prestação de um serviço.

No entanto, em razão da dificuldade em identificar uma situação em que não existam custos de transação, Douglas North (2006, p. 14) economista que, assim como Coase, é associado às teorias que integram a chamada Nova Economia Institucional, desenvolveu uma análise sobre o papel que as instituições desempenham nos arranjos negociais, com impacto nos custos de transação.

Instituição, nessa perspectiva, é toda restrição criada pelo ser humano de modo a moldar interações, como regras formais (leis, códigos) ou limitações informais (convenções, códigos de conduta). Também funcionariam como instituições os órgãos e mecanismos responsáveis pela eficácia destas normas, como o Poder Judiciário.

Para o autor, instituições eficientes seriam capazes de reduzir os custos de transação, por diminuírem incertezas e limitarem opções indesejáveis entre os agentes envolvidos em determinada circunstância (NORTH, 2006, p. 32; 1990, p. 27).

$\mathrm{Ou}$ seja, quanto melhores forem as instituições criadas, menores serão os custos de transação envolvidos, pois os agentes (indivíduos) estariam propensos a solucionar eventuais problemas a partir de negociações, com receio de serem repreendidos caso assim não o fizessem. Assim, o problema da desconfiança entre as partes seria solucionado a partir de instituições seguras e que garantissem eventuais acordos firmados.

Com base nas explicações dos autores e analisando o próprio Direito como uma espécie de instituição responsável pela confiança no mercado privado, em um sentido amplo, a tributação em si poderia ser considerada um custo de transação. A conclusão decorre do fato da carga tributária ser um fator fundamental para a determinação da estrutura de uma operação societária, a concretização de um negócio, o risco da sonegação fiscal, a transferência de uma planta produtiva (a exemplo do impacto da tributação do ICMS e ISS), assim como nos casos de expansão das atividades. 
No entanto, o enfoque a que se propõe o artigo centra-se nos custos de transação ocultos, ou seja, no desembolso das organizações com deveres instrumentais (ou obrigações acessórias) associados ao cumprimento de prestações de fazer impostas pela Administração Pública e que acarretam custos que não são necessariamente identificados de imediato.

\section{OS DEVERES INSTRUMENTAIS COMO CUSTOS DE TRANSAÇÃO}

Conforme visto, o tributo é indispensável ao funcionamento da administração pública por representar a principal fonte de receita do mecanismo estatal.

Por tributo, compreende-se o resultado do cumprimento da “obrigação principal”, ou seja, da prestação pecuniária imposta ao sujeito (contribuinte), por lei, de arcar com certa quantia que será destinada aos cofres públicos.

No entanto, dada a grande complexidade do sistema, existem determinadas prestações impostas aos contribuintes que facilitam o trabalho de fiscalização e arrecadação da administração pública, mas que não se enquadram na categoria do tributo.

Em matéria de direito tributário, a locução "obrigação acessória" é utilizada para designar o cumprimento da regra estabelecida no art. 113, $\S 2^{\circ}$ do Código Tributário Nacional. Nos termos do referido dispositivo, a "obrigação acessória decorre da legislação tributária e tem por objeto as prestações, positivas ou negativas, nela previstas no interesse da arrecadação ou da fiscalização dos tributos".

Em outras palavras, aquilo que se convencionou denominar de obrigações acessórias seriam prestações que não resultam no pagamento do tributo propriamente dito, mas sim em um fazer ou não fazer algo destituído de natureza patrimonial.

Decorrem de ações que buscam facilitar o controle, arrecadação e fiscalização de determinado tributo, mas que com ele não se confundem.

Esta é a razão pela qual Carvalho (2014, p. 288-289) prefere utilizar a expressão dever instrumental, e não obrigação acessória, na medida em que estas prestações não possuem cunho patrimonial. Além do que, há deveres que não circundam vínculos obrigacionais (pagar tributo), de modo que estes deveres nem sempre serão acessórios.

São exemplos destas prestações os casos de regras que estabelecem: (i) a necessidade de determinado cadastro prévio no ente tributante; (ii) elaboração e escrituração de determinados livros fiscais; (iii) elaboração de declarações para o cálculo do montante devido; (iv) atendimento de solicitações das autoridades fiscais, dentre outros.

Horvath (2006, p. 206-207) explica que os deveres instrumentais decorrem de um dever de colaboração dos contribuintes para com a Administração Pública, obviamente em decorrência de uma exigência legal. Trata-se de um dever em decorrência do poder de império do Estado de impor tarefas até então inerentes à atividade pública, dada à impossibilidade do exercício dessa atividade de maneira exclusiva pela autoridade.

No entanto, a despeito da necessidade destas prestações à arrecadação tributária, não há como negar que os deveres instrumentais (obrigações acessórias) aumentam o custo da atividade privada.

Afinal de contas, a delegação, cada vez maior, das funções públicas aos particulares, mais do que ônus em razão do tempo despendido no cumprimento dos deveres, por vezes justificam a aplicação de severas penalidades pelo inadimplemento de tais prestações de fazer ou não fazer.

Normalmente, discute-se o total da carga tributária de um país e os eventuais aumentos dela decorrentes sobre os custos de uma determinada atividade econômica. No entanto, estes deveres instrumentais ao cumprimento da obrigação principal (pagamento do tributo) são normalmente desconsiderados nessa perspectiva.

Trata-se do motivo pelo qual Carvalho (2006, p. 86) afirma que "do ponto de vista da racionalidade econômica (custo/benefício) o grau de burocracia brasileira passa a tornar proibitivo 
o cumprimento de deveres instrumentais, criando incentivos para a evasão fiscal e a informalidade".

O autor explica que a própria estrutura da norma tributária, do tipo primária com modal obrigatório, traz uma maior complexidade e exigência de participação do destinatário do que o Direito Penal, por exemplo, que opera exclusivamente pela via da prescrição de sanção pelo descumprimento de determinada obrigação (CARVALHO, 2006, p. 88).

$\mathrm{Ou}$ seja, no Direito Tributário exige-se uma prestação do contribuinte para apenas posteriormente calcular o valor do tributo devido e, acaso o montante não esteja de acordo com o entendimento do agente fiscalizador, penalidades serão impostas, não apenas pela ausência do recolhimento da obrigação principal, mas também por eventuais inconsistências na obrigação de fazer exigida do contribuinte.

As penalidades são severas, com multas que podem chegar a mais de $100 \%$ do valor do tributo envolvido na operação, sendo muitas vezes aplicáveis sobre os valores das operações. Ou seja, muitas vezes superando o custo do cumprimento da própria obrigação principal.

Normalmente, inclusive, não há qualquer tipo de prazo concedido ao contribuinte para que as falhas em suas declarações possam ser corrigidas, mesmo diante da complexidade do sistema tributário brasileiro. Trata-se dos custos de conformidade à tributação brasileira.

Assim, ainda que indiretamente, diante do receio das possíveis penalidades envolvidas na operação e dos exacerbados custos nestas hipóteses, a complexidade faz surgir outros tipos de desembolsos, como eventuais consultorias de profissionais especializados na área que auxiliam a evitar os riscos impostos pelo sistema.

Por outro lado, os deveres instrumentais possuem limitação constitucional na garantia prevista no art. 170 do texto constitucional que assegura a todos o livre exercício de qualquer atividade econômica, independentemente de autorização de órgãos públicos, salvo nos casos previstos em lei. Sem sombra de dúvidas, caso os deveres instrumentais representem ônus significativo que resulte na própria limitação da atividade, a referida exigência caracterizaria uma afronta ao texto constitucional.

Tais obrigações de fazer impostas pelo Estado estão associadas à burocracia e frequentemente trazem exigências onerosas para os contribuintes, fruto de uma transferência de obrigação que deveria recair sobre o Estado. Os contribuintes, neste caso, podem ser duplamente penalizados ao suprirem as exigências do Estado e incorrerem em penalidades pela ausência de conhecimento e preenchimento equivocado de declarações e demais deveres impostos.

Recentes pesquisas indicam que o Brasil edita cerca de 800 normas por dia, sendo 5,4 milhões desde a promulgação da Constituição de 1988. Do total, foram editadas 363.779 normas tributárias, o que representa mais de 1,88 normas tributárias por hora em um dia útil (IBPT, 2017). Ainda, o Brasil seria o segundo colocado no ranking dos países com maior complexidade tributária, em 2017, no mundo (TMF Group, 2017).

Os dados revelam a dificuldade ou até mesmo impossibilidade de identificação de todas as possíveis alterações legislativas nos níveis municipal, estadual e federal, especialmente ao se considerar que um mesmo fato tributário possa se sujeitar a diferentes interpretações das pessoas de direito público envolvidas, sempre na busca do enquadramento em favor da respectiva imposição tributária.

Fatores como este justificam o fato de que o Brasil ocupe apenas o $123^{\circ}$ lugar (de um total de 190) no ranking de países em termos de facilidade para a realização de negócios, segundo pesquisa divulgada pelo Banco Mundial (DOING BUSINESS, 2017), sendo que o Índice de Complexidade Financeira de 2017 da TMF Group, indicou o país como o $2^{\circ}$ lugar no mundo dentre os locais mais complexos em matéria de compliance das obrigações contábeis e fiscais.

Aliás, tais deveres acessórios ou instrumentais ao pagamento do tributo, a despeito de recaírem sobre os contribuintes e significarem evidente ônus adicional imposto às suas atividades, representam prova em seu desfavor, quando diante de eventual litígio administrativo e judicial. 
Por exemplo, a simples emissão de documento fiscal não exigido pelo fisco ou a ausência de escrituração que não represente qualquer ausência de pagamento de tributo podem resultar na aplicação de penalidades, independentemente do resultado em termos de perda tributária provocada pelos supostos equívocos.

Ou seja, além do altíssimo nível burocrático, o contribuinte deve conviver com o risco de que a informação repassada com algum equívoco ao ente tributante possa resultar na implicação de penalidade superior ao valor do próprio tributo que seria previamente devido ou valores que sequer seriam cobrados em operações desoneradas pela tributação. Trata-se, pois, de ônus oculto no Direito Tributário.

Infelizmente, tais inconsistências do sistema são totalmente incompatíveis com os objetivos de um Estado Democrático de Direito. Criou-se um sistema complexo, com diferentes competências, que demanda um número infindável de normas editadas com a pretensão de serem compreendidas e cumpridas pelos contribuintes.

Obviamente, um potencial investidor, diante de tamanha complexidade e empecilhos ao desenvolvimento da atividade empresarial, possui a prerrogativa de simplesmente deixar de investir em determinada atividade ou evitar certos caminhos com a pretensão de se esquivar à coerção legalmente imposta.

No campo da tributação, portanto, são vários os exemplos de como o Direito interfere na economia e no desenvolvimento de determinado setor.

Para Carvalho (2004, p. 63) o que ocorre nessas situações seria a interferência e não a intervenção direta de um sistema sobre o outro. Isto porque "por certo a normatização perturba a ordem econômica, mas, ao menos dentro de um Estado Democrático de Direito, não a domina inteiramente, pois as normas sempre serão processadas dentro do código binário econômico (ter/não ter o custo/benefício)".

Ou seja, sempre há opções ao destinatário da imposição, de modo a cumprir ou não às regras estabelecidas, diante da análise dos custos envolvidos. A sonegação, neste caso, a despeito de ser negativa do ponto de vista moral e de sua ilicitude, pode significar uma alternativa menos onerosa às organizações em determinada circunstância. O sistema normativo aparece aqui funcionando como um indutor negativo de condutas em razão da perda de sua razoabilidade.

Em última análise, dentro de um sistema extremamente complexo, cujos deveres instrumentais, em conjunto com uma carga excessiva, subsistam ao ponto de afetar de forma significativa o desenvolvimento da atividade econômica, o empresário normalmente trabalha com dois cenários: (i) a assunção de riscos pela informalidade ou descumprimento das regras impostos pela Administração Pública; (ii) retirar o investimento originalmente proposto e identificar outros locais ou alternativas para a aplicação dos recursos com maior segurança jurídica e liberdade.

Sobre a excessiva onerosidade do direito tributário e cumprimento dos deveres instrumentos, Carvalho (2004, p. 67) esclarece que:

[...] nos países democráticos de intensa tributação, diversos segmentos da economia também operam do lado ilícito do direito. Contratando funcionários sem registro, vendendo mercadorias ou prestando serviços sem a emissão de notas fiscais, etc. Tal onerosidade fiscal acaba gerando uma resposta não só da economia, como também da moral, com vistas a justificar as condutas dos indivíduos. Destarte, o que era moralmente condenável, como por exemplo a sonegação, pode passar a ser vista como uma conduta correta, oposta à injustiça do sistema tributário.

Assim, a própria noção moral do não pagamento de tributos acaba sendo desvirtuada, sob a justificada de que o ônus excessivo tributário justificaria a sonegação. O resultado, ao contrário da diminuição de tributos e da simplificação das exigências dos deveres instrumentais, é o contínuo aumento da carga tributária aos contribuintes adimplentes. 
Uma reforma tributária que preze pela simplificação seria uma alternativa ponderável para a solução do problema associado ao incremento contínuo da carga tributária, entretanto, até mesmo a solução depende de interesses outros que não o próprio ordenamento jurídico e complexidade tributária.

Diante das dificuldades mencionadas, importa destacar a recente e importante publicação do "Programa de Estímulos à Conformidade Tributária Nos Conformes", instituído pelo estado de São Paulo por meio da Lei Complementar n 1.320/2018.

O referido programa possui, como objetivo principal, uma melhoria no relacionamento entre os contribuintes estaduais paulistas e a fazenda pública, criando um ambiente de confiança entre as partes e a possibilidade de autorregularização de eventuais pendências identificadas nos livros e documentos fiscais dos administrados.

Além de melhorar o relacionamento entre fisco e contribuinte, o programa promete reduzir os custos vinculados ao compliance com as obrigações fiscais imputadas às empresas e reduzir as penalidades envolvidas no cumprimento das normas emitidas pelo Estado.

Os benefícios aplicados aos contribuintes, como a possibilidade de transferências de créditos, processos de restituição simplificados e acesso a procedimentos de Análise Fiscal Prévia, serão concedidos de acordo com classificações atribuídas aos contribuintes de acordo com a regularidade fiscal no cumprimento das obrigações, principais e acessórias, impostas para a apuração do imposto dentro do território paulista.

Obviamente, o sucesso do Programa ainda depende da efetiva aplicação das normas editadas, imposição de regras claras e da mudança cultural na confiança estabelecida na relação fisco contribuinte.

No entanto, trata-se de importante passo e exemplo de mecanismo para a redução dos custos de transação, iniciativa e de concretização da eficiência da máquina pública.

\section{OS DEVERES INSTRUMENTAIS E O SIGILO DE DADOS}

Indo adiante, é importante destacar outro fator de impacto no adimplemento dos deveres instrumentais impostos pela Administração Pública: o risco quanto ao sigilo de dados. Muitas das prestações de fazer impostas pelas fazendas públicas estão atreladas à divulgação de informações sigilosas, que não seriam facilmente identificadas por pessoas alheias às atividades econômicas do contribuinte.

Veja-se, por exemplo, a obrigação imposta pelo chamado "bloco K" do SPED FISCAL (EFD ICMS IPI - Ajuste SINIEF n 25/2016), vinculada às informações atreladas à tributação do ICMS e IPI, criado no bloco de escrituração digital para o devido controle da formação dos estoques das empresas sujeitas aos referidos tributos.

Com a nova imposição de fazer, os contribuintes foram obrigados a declarar ao físco informações relacionadas à quantidade de itens produzidos em suas atividades industriais, tipos e quantidades de insumos consumidos, bem como movimentação de estoques próprios e de terceiros.

A intenção inicial da nova imposição foi o combate à sonegação fiscal, de modo que eventuais diferenças nos inventários das indústrias e no consumo poderão resultar em novos questionamentos por parte da fazenda.

De todo modo, para além do evidente custo no cumprimento da nova exigência e parametrização de sistemas internos próprios que atendam as informações descritas na escrituração digital, um dos principais receios dos contribuintes com o cumprimento do dever acessório decorre do sigilo de dados, principalmente fórmulas e composição de produtos industriais.

Obviamente, para uma indústria que produza um produto comum, com vários concorrentes similares no mercado, a divulgação da quantidade dos itens utilizados no processo produtivo talvez não traga impacto significativo. No entanto, para empresários que atuem com estratégias ou conhecimentos muito específicos a divulgação pode criar dificuldades 
concorrenciais adicionais. Tal situação poderia, inclusive, induzir que a decisão quanto a assumir o risco da aplicação de penalidades seja mais interessante do que o cumprimento da prestação imposta, frustrando-a.

Não se trata de evitar toda divulgação de informação às autoridades competentes, que dependam destes dados para cumprir a atividade de fiscalização e constituição do crédito tributário, mas do reconhecimento da existência de fatores que trazem riscos ao próprio segredo industrial e sigilo de informações essenciais ao desenvolvimento da atividade econômica, não condizentes com a justificativa de colaboração.

Tamanha é a complexidade deste dever instrumental que a recente Lei de Liberdade Econômica (Lei n. ${ }^{\circ}$ 13.874/19) indicou expressamente que a referida exigência seria substituída, assim como o Sistema de Escrituração Digital das Obrigações Fiscais, Previdenciárias e Trabalhista, por um sistema mais simplificado.

É dizer, após a criação e exigência das informações, com os consequentes custos impostos aos contribuintes, foi preciso uma nova Lei reconhecendo a inviabilidade e complexidade da exigência anteriormente imposta, com a promessa de que o sistema seria revisto com o objetivo de simplificação.

Ao citar o direito ao sigilo de dados (art. $5^{\circ}$, XII da Constituição Federal), à intimidade e à vida privada (art. $\left.5^{\circ}, \mathrm{X}\right)$, Horvath $(2006$, p. 215) sugere que é preciso sopesar "o grau de necessidade, para o Fisco, de obter dados do contribuinte, isto é, se é realmente imprescindível o acesso a determinadas informações pessoais para que o tributo possa ser cobrado".

Pode-se dizer mais, conforme demonstrado, os custos ocultos de transação vinculados aos deveres instrumentais, caso imprevistos e não computados de maneira correta ao planejado para determinado período, significam verdadeira afronta à livre iniciativa, prevista nos artigos $1^{\circ}$, inciso IV, e 170 do texto constitucional.

Neste caso, o direito, ao invés de trazer segurança às relações negociais, acaba por induzir a fixação de preços e até mesmo limitação ao exercício da liberdade econômica e resultar na fuga de investimentos no país. Trata-se da digitalização da burocracia.

\section{CONSIDERAÇÕES FINAIS}

Para a legitimidade do sistema tributário, não basta a análise da consistência da regra matriz de incidência dos tributos instituídos em conformidade com as regras estabelecidas pela Constituição, mas igualmente a pertinência do objetivo da cobrança e sua conformidade com os propósitos constitucionais de promoção do desenvolvimento da sociedade brasileira e da livre iniciativa.

Alíquotas e carga tributária extremamente altas e a complexidade do sistema, longe de serem ferramentas eficientes utilizadas pelo Poder Público, tendem a resultados totalmente diversos, como a fuga dos agentes econômicos, sonegação, planejamentos fiscais ilícitos, redução do consumo e investimentos.

Trata-se de um ciclo vicioso, em que uma maior tributação necessita maiores retornos com base em políticas públicas, e maiores gastos públicos tendem a conduzir ao aumento da carga tributária do país.

No entanto, caso o sistema se torne extremamente oneroso, a ponto de não mais ser eficiente e válido do ponto de vista econômico, os investimentos realizados (e que proporcionam o incremento da arrecadação) são dispersos, diminuindo a arrecadação anteriormente disponível aos cofres públicos.

O desconhecimento da real carga tributária brasileira, considerando o conjunto de tributos diretos e indiretos, reduzem a clareza e a eficiência do sistema, especialmente ao se considerar o nível da imposição tributária no país. 
Há, ainda, a necessidade de se reconhecer os altos custos de transação impostos ao empresariado, inclusive no que diz respeito ao cumprimento e gestão das exigências fiscais que consomem boa parte dos recursos dos indivíduos e que não são incluídos nos valores imputados diretamente aos contribuintes.

A simplificação do sistema tributário, mais do que uma necessidade de caráter prioritário, tende a evitar o descumprimento das normas impostas, facilitar a fiscalização, diminuir o risco de fraudes sob a justificativa de complexidade dos deveres instrumentais, além de ser menos onerosa para o próprio Estado.

A falta de confiança na legitimidade da arrecadação e administração das políticas públicas dificulta ainda mais o sentimento de solidariedade que deve estar relacionado ao recolhimento dos recursos necessários para fazer frente ao custo de manutenção do Estado e de suas finalidades.

Não se trata apenas de uma solução para a simplificação do sistema, mas de um conjunto de práticas por parte da administração pública e cidadãos que resulte nos objetivos originais propostas pelo texto constitucional e que sejam eficientes do ponto de vista econômico, em razão dos objetivos originalmente propostos pelas regras jurídicas criadas.

A aplicação da Análise Econômica ao Direito Tributário, a despeito das críticas a ela impostas, mostra-se pertinente de modo a auxiliar na melhoria do sistema tributário nacional, quer seja no que diz respeito aos limites arrecadatórios, quer seja em relação às obrigações acessórias.

Não se trata de afirmar que a hermenêutica tributária deva se valer apenas dos efeitos econômicos, mas que a melhor técnica jurídica deve promover a justiça e eficiência sempre com o objetivo do bem estar social.

Tanto o Direito como a Economia encontram seu fundamento último nas relações sociais. O Direito Tributário, a seu turno, regula as condutas pessoais dos contribuintes, de modo que qualquer alteração na conduta dos agentes econômicos deve igualmente interferir na forma como as regras jurídicas são criadas e aplicadas, sob pena de serem imprestáveis aos propósitos originais.

\section{REFERÊNCIAS}

BRASIL. Supremo Tribunal Federal. Ação Direta de Inconstitucionalidade $n^{\circ} 4481$. Lei estadual que institui benefícios fiscais relativos ao ICMS. Ausência de convênio interestadual prévio. Ofensa ao art. 155, § 2 , XII, G, DA CF/88. Requerente: Confederação Nacional da Indústria; Intimados: Governador do Estado do Paraná e Assembleia Legislativa do Estado do Paraná. Brasília, DF, 11 de março de 2015. Disponível em: http://stf.jus.br/portal/jurisprudencia/listarJurisprudencia.asp?s1=\%28ADI\%24\%2ESCLA\%2E+E $+4481 \%$ 2ENUME $\% 2 \mathrm{E} \% 29+\mathrm{OU}+\% 28 \mathrm{ADI} \% 2 \mathrm{EACMS} \% 2 \mathrm{E}+\mathrm{ADJ} 2+4481 \% 2 \mathrm{EACMS} \% 2 \mathrm{E} \% 29 \&$ base=baseAcordaos\&url=http://tinyurl.com/kd6286p. Acesso em: 20 de outubro de 2018.

BUCHANAN, James McGill; TULLOCK, Gordon. The calculus of consent: Logical Foundations of Constitucional Democracy. Indianápolis: Liberty Fund, 2004.

CARVALHO, Cristiano. Deveres Instrumentais e Custos de Transação. In: CONGRESSO DO IBET,III, 2006. São Paulo: Noeses, 2006.

CARVALHO, Cristiano. Tributação e Economia - Uma Introdução à Análise Econômica do Direito Tributário. In: II CONGRESSO DO IBET. São Paulo: Noeses, 2004.

CARVALHO, Paulo de Barros. Curso de Direito Tributário. 23 ed. São Paulo: Saraiva, 2011.

CARVALHO, Paulo de Barros. Curso de Direito Tributário. 26. ed. São Paulo: Saraiva, 2014. 
COASE, Ronald H. O problema do custo social. In: SALAMA, Bruno Meyerhof. Direito e Economia - Temas Escolhidos. São Paulo: Saraiva, 2010.

COASE, Ronald H. O problema do custo social. Tradução de Francisco Kümmel F. Alves e Renato Vieira Caovilla. 1960. Disponível em: <http https://edisciplinas.usp.br/pluginfile.php/2123990/mod_resource/content/1/custosocial.pdf $>$. Acesso em: 21 de setembro de 2018.

COOTER, Robert Dandridge; SCHAFER, Hans-bernd. O Nó de Salomão: Como o Direito pode erradicar a pobreza das Nações. Curitiba: Crv, 2017.

DOING BUSINESS 2017. Igualdade de Oportunidade para Todos. 14 ed. Disponível em: http://portugues.doingbusiness.org/reports/global-reports/doing-business-2017.

GRUPENMACHER, Betina Treiger. Das Exonerações Tributárias. Incentivos e Benefícios fiscais. In: GRUPENMACHER, Betina Treiger et al. Novos Horizontes da Tributação: Um diálogo luso-brasileiro. Coimbra: Ed. Almedina, 2012, p.17

HORVATH, Estevão. Deveres Instrumentais e Custos de Transação. In: CONGRESSO DO IBET. São Paulo: Noeses, 2006.

IBPT. "Brasil edita cerca de 800 normas por dia somando 5,4 milhões desde a Constituição de 1988". https://ibpt.com.br/noticia/2603/Brasil-edita-cerca-de-800-normas-por-dia-somando-5-4milhoes-desde-a-Constituicao-de-1988, em 10.08.2017.

NORTH, Douglass C. Custos de transação, instituições e desempenho econômico. Tradução de Elizabete Hart. 3. ed. Rio de Janeiro: Instituto Liberal, 2006.

NORTH, Douglass C. Institutions, Institutional Change and Economic Performance. New York: Cambridge University Press, 1990.

SILVEIRA, Paulo Antônio Caliendo Velloso da. Direito Tributário e Análise Econômica do Direito: uma visão crítica. Rio de Janeiro:Elsevier, 2009.

VIVERDOS DE CASTRO, Augusto Olympio. História Tributária do Brasil. 2 ed. Brasília: ESAF, 1989.

RECEITA FEDERAL. "IBPT: A cada R $\$ 100$ que o contribuinte recebe, $\mathrm{R} \$ 33$ fica com o governo". IBPT, 10 de agosto de 2017. https://www.ibpt.org.br/.

RIBEIRO, Márcia Carla; GALESKI JUNIOR, Irineu. Teoria geral dos contratos: contratos empresariais e análise econômica. 2. ed. São Paulo: Editora Revista dos Tribunais, 2015

TMF GROUP. “The Financial Complexity Index 2017”. TMF Group, junho de 2017. https://www.tmf-group.com/en/news- insights/publications/2017/financial-complexity-index$\underline{2017}$. 